\title{
Evaluation of Manual Ultrasonic Examinations Applied to Detect Flaws in Primary System Dissimilar Metal Welds at North Anna Power Station
}

MT Anderson

AA Diaz

SR Doctor

June 2012

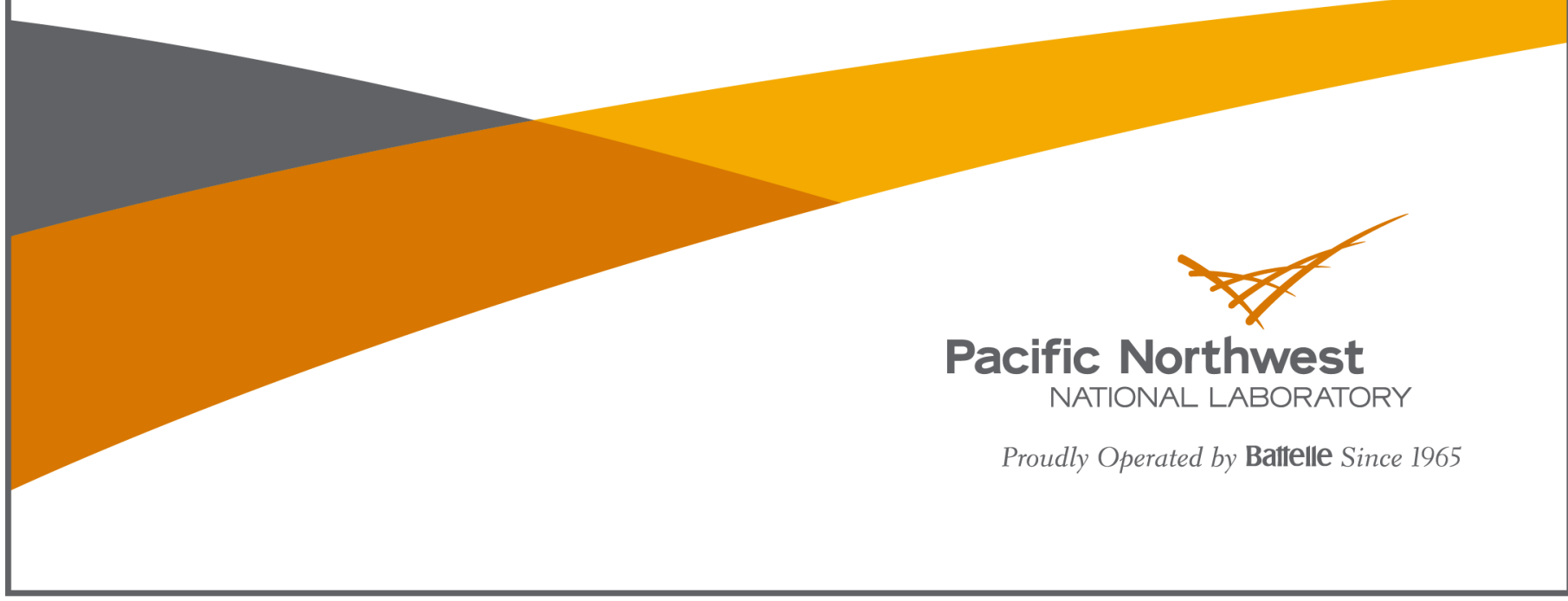




\title{
DISCLAIMER
}

This report was prepared as an account of work sponsored by an agency of the United States Government. Neither the United States Government nor any agency thereof, nor Battelle Memorial Institute, nor any of their employees, makes any warranty, express or implied, or assumes any legal liability or responsibility for the accuracy, completeness, or usefulness of any information, apparatus, product, or process disclosed, or represents that its use would not infringe privately owned rights. Reference herein to any specific commercial product, process, or service by trade name, trademark, manufacturer, or otherwise does not necessarily constitute or imply its endorsement, recommendation, or favoring by the United States Government or any agency thereof, or Battelle Memorial Institute. The views and opinions of authors expressed herein do not necessarily state or reflect those of the United States Government or any agency thereof.

\author{
PACIFIC NORTHWEST NATIONAL LABORATORY \\ operated by \\ BATTELLE \\ for the \\ UNITED STATES DEPARTMENT OF ENERGY \\ under Contract DE-AC05-76RL01830 \\ Printed in the United States of America \\ Available to DOE and DOE contractors from the \\ Office of Scientific and Technical Information, \\ P.O. Box 62, Oak Ridge, TN 37831-0062; \\ ph: (865) 576-8401 \\ fax: (865) 576-5728 \\ email: reports@adonis.osti.gov \\ Available to the public from the National Technical Information Service, \\ U.S. Department of Commerce, 5285 Port Royal Rd., Springfield, VA 22161 \\ ph: (800) 553-6847 \\ fax: $(703) 605-6900$ \\ email: orders@ntis.fedworld.gov \\ online ordering: http://www.ntis.gov/ordering.htm
}

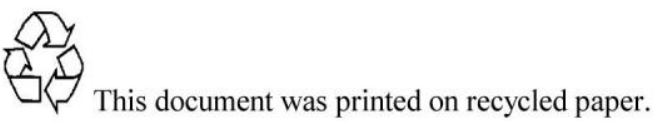

$(9 / 2003)$ 


\section{Evaluation of Manual Ultrasonic Examinations Applied to Detect Flaws in Primary System Dissimilar Metal Welds at North Anna Power Station}

MT Anderson

AA Diaz

SR Doctor

June 2012

Prepared for

the U.S. Department of Energy

under Contract DE-AC05-76RL01830

Pacific Northwest National Laboratory

Richland, Washington 99352 



\section{Acronyms and Abbreviations}

$\begin{array}{ll}\text { CAD } & \text { computer-aided drafting } \\ \text { DMW } & \text { dissimilar metal weld } \\ \text { EPRI } & \text { Electric Power Research Institute } \\ \text { HiP } & \text { hot iso-statically pressed } \\ \text { ID } & \text { inside diameter } \\ \text { ISI } & \text { inservice inspection } \\ \text { NRC } & \text { U.S. Nuclear Regulatory Commission } \\ \text { OD } & \text { outside diameter } \\ \text { PA } & \text { phased array } \\ \text { PDI } & \text { Performance Demonstration Initiative } \\ \text { PNNL } & \text { Pacific Northwest National Laboratory } \\ \text { PWSCC } & \text { primary water stress corrosion cracks } \\ \text { SNR } & \text { signal-to-noise ratio } \\ \text { TJ } & \text { technical justification } \\ \text { UT } & \text { ultrasonic testing }\end{array}$





\section{Contents}

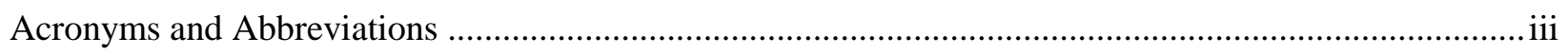

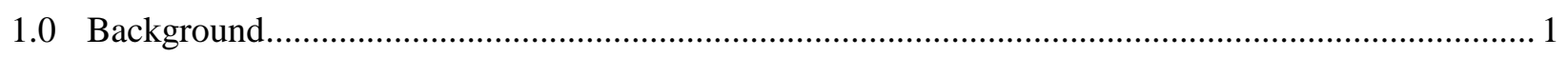

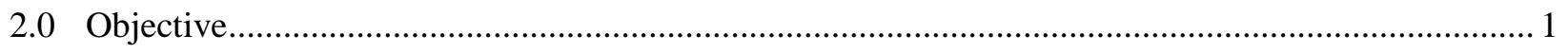

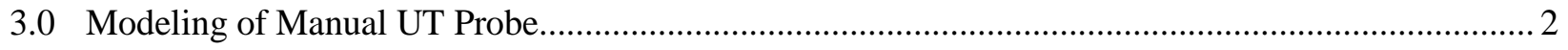

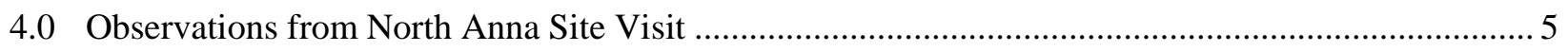

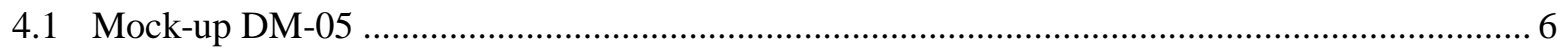

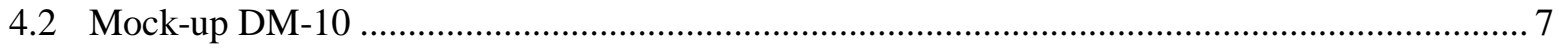

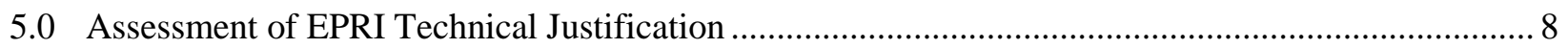

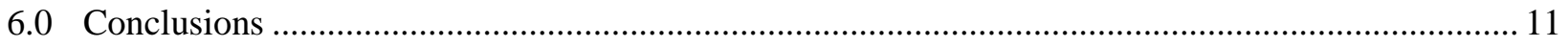

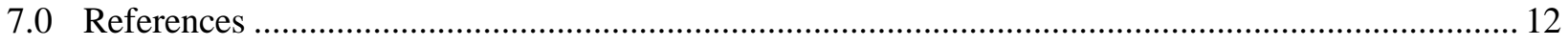

Appendix A - Description of North Anna Mock-ups ....................................................................... A. 1

Appendix B - A-scans on North Anna Mock-ups ................................................................................... 


\section{Figures}

1 Profile of the North Anna Steam Generator DMW ….................................................................. 2

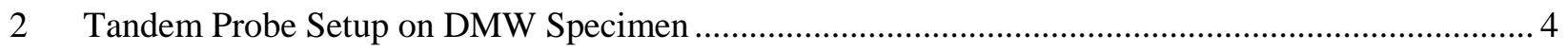

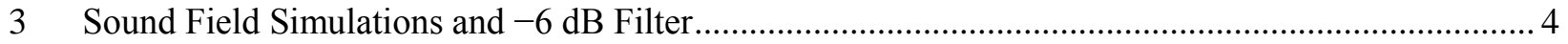

4 Simulated Sound Field at ID with a -12 dB Filter ..................................................................... 5

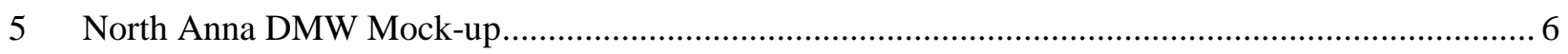

6 Mid-wall Fabrication Flaws or Implantation Artifacts Detected in North Anna Mock-ups (as

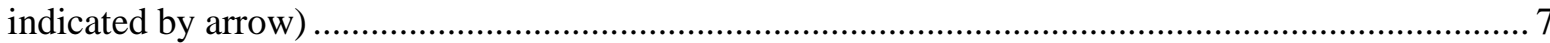

\section{Tables}

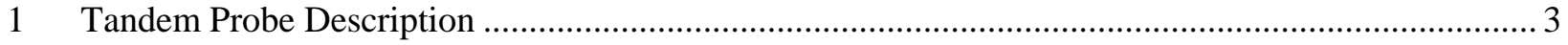




\subsection{Background}

During a recent inservice inspection (ISI) of a dissimilar metal weld (DMW) in an inlet (hot leg) steam generator nozzle at North Anna Power Station Unit 1, several axially oriented flaws went undetected by the licensee's manual ultrasonic testing (UT) technique. The flaws were subsequently detected as a result of outside diameter (OD) surface machining in preparation for a full structural weld overlay. The machining operation uncovered the existence of two through-wall flaws, based on the observance of primary water leaking from the DMW. Further ultrasonic tests were then performed, and a total of five axially oriented flaws, classified as primary water stress corrosion cracking (PWSCC), were detected in varied locations around the weld circumference.

The North Anna hot leg safe end-to-nozzle weld configuration has an approximate 11-degree OD taper from the thinner austenitic piping side up to the thicker carbon steel nozzle, and is typical of a DMW created during steam generator replacement at Westinghouse-designed plants. However, the level of OD taper exhibited by this particular design is not included as a blind performance demonstration mock-up used by the industry's Performance Demonstration Initiative (PDI), which is administered by the Electric Power Research Institute (EPRI). For this reason, the licensee engaged EPRI to assist in the development of technical justification (TJ) IR-2009-358 (EPRI 2009), to support the basis for a sitespecific qualification.

\subsection{Objective}

The U.S. Nuclear Regulatory Commission (NRC) Office of Research requested Pacific Northwest National Laboratory (PNNL) to assess the manual UT technique that was applied at North Anna, and evaluate potential causes for the failure of the examination to detect these significant flaws. The purpose of the PNNL assessment is to provide insights as to the nature of the event and provide a technical basis for regulatory consideration. Three factors have been identified that make it difficult to determine an exact cause of the UT detection failure. The first is that the licensee conducted manual non-encoded (real-time) UT examinations. Non-encoded examinations produce essentially no data for review so it cannot be judged whether the data quality was sufficient to discriminate the flaws from other weld reflections or ambient noise, or whether the flaw responses were evident, but simply missed during the examination. The second factor is that pre-overlay OD machining operations eliminated the OD taper and reduced the metal path. Thus, the modified configuration could have significantly improved acoustic transmission for post-machining UT flaw detection. Finally, the third factor is that the machining may have changed residual stresses which could have changed certain crack dimensions making the flaws more detectable.

To accomplish these objectives, PNNL was asked to perform the following activities:

- Model the acoustic performance of the manual UT probe arrangement used at North Anna to analyze its potential to detect inside diameter (ID) surface-connected, axially oriented flaws, given predicted sound field characteristics;

- Visit the North Anna site to evaluate the actual probe and UT responses produced from site-specific DMW flaw mock-ups; and 
- Assess (TJ) IR-2009-358, developed by EPRI, for qualification acceptance of the manual technique that was applied.

These activities will be reported in the remaining sections of this report, followed by initial PNNL conclusions. It should be noted that further work is being planned to augment these findings and assist in generic regulatory assessments; however, initial conclusions are reported herein to support expedited resolution of NRC Regional findings for the North Anna Power Station.

\subsection{Modeling of Manual UT Probe}

The North Anna steam generator nozzle DMW configuration consists of an 11-degree OD-tapered safe end beginning at a through-wall thickness of $83.12 \mathrm{~mm}(3.275 \mathrm{in}$.) and ending at the weld toe with a thickness of $121.16 \mathrm{~mm}$ (4.770 in.) nominally. The Inconel 82/182 weld and butter regions continue to follow the 11-degree OD taper into the 508 Class 2 steel nozzle forging, as shown in Figure 1. A threedimensional computer-aided drafting (CAD) drawing of this specimen was rendered for modeling purposes.

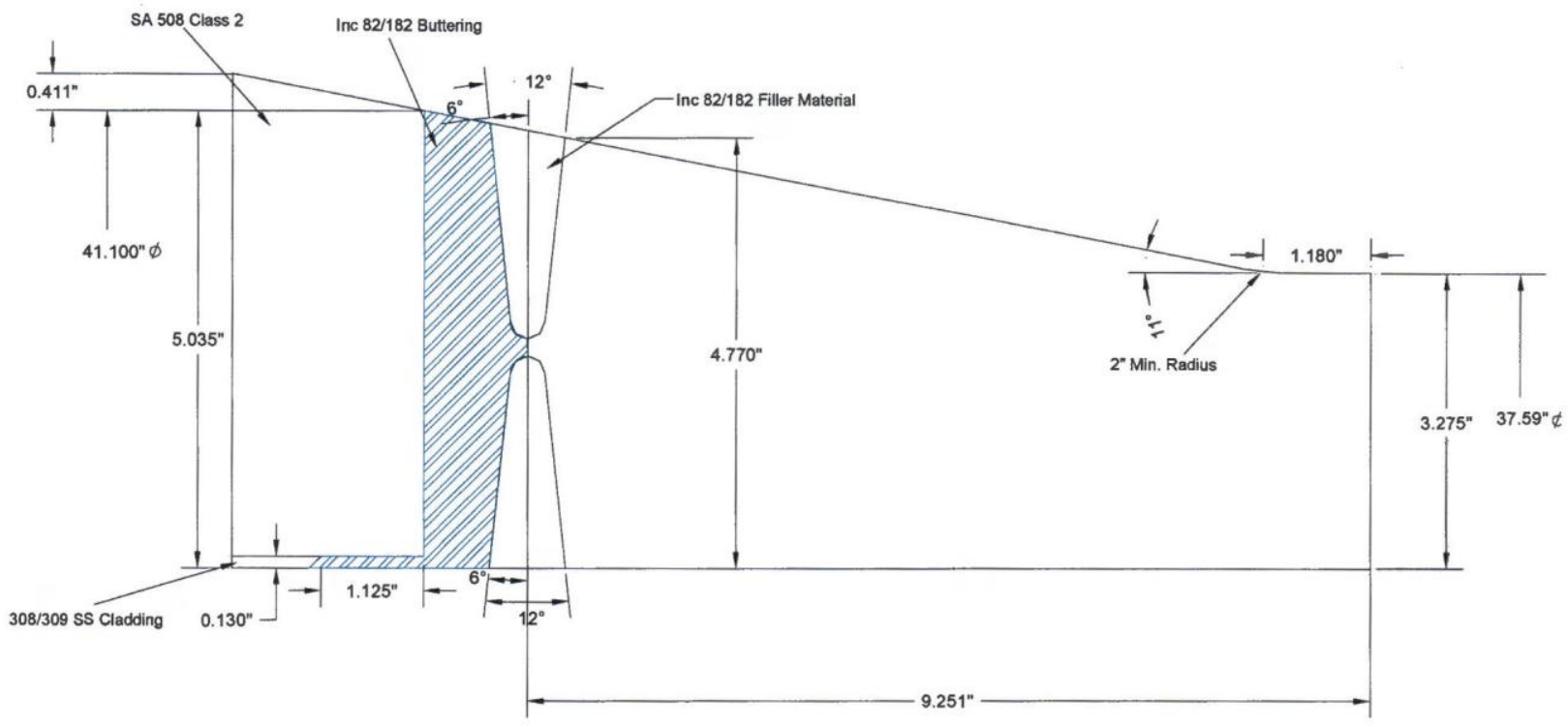

Figure 1. Profile of the North Anna Steam Generator DMW

As outlined in (TJ) IR-2009-358, the manual UT method included the use of a 1.0-MHz pitch-catch tandem (front-rear configuration) set of probes used during circumferential scanning for detection of axial flaws located in/near the weld region. The probes, manufactured by Sigma Transducers (Kennewick, Washington), were designed to generate a refracted longitudinal sound wave at a 40-degree ID impingement angle in the specimen. The probe sets have wedges with roof angles of 4.66-degrees to redirect the sound beams laterally (in the axial direction on the pipe) to accommodate the 11-degree OD taper on the weld. The probe sets are designated as "LR" and "RR" relating to the scan direction; LR for left, or counterclockwise, if facing the nozzle from the pipe side, and RR for right, or clockwise as viewed 
from the pipe side. Sigma Transducers was contacted and provided the details of the integral probe/wedge configurations; these can be found in Table 1. The information in Table 1 is for the LR probe set, and only this direction has been modeled; the RR probe set would produce a mirror image if modeled.

Table 1. Tandem Probe Description

\begin{tabular}{|c|c|}
\hline Design & 2007 Integral Probe/Wedge \\
\hline Manufacturer & Sigma Transducers \\
\hline Frequency & $1.0 \mathrm{MHz}$ \\
\hline Bandwidth & $52 \%$ at $-6 \mathrm{~dB}$ \\
\hline Damping material & Backed, not inductively tuned \\
\hline Angle/mode & 40-degree L \\
\hline Examination type & Circumferential scan \\
\hline Element size & $2 \times(25 \times 25) \mathrm{mm}[2 \times(1.0 \times 1.0)$ in. $]$ \\
\hline Pulser-receiver & Front-transmit; rear-receive \\
\hline Wedge material & Low 10 \\
\hline Wedge velocity & $2449 \mathrm{~m} / \mathrm{s}(0.964 \mathrm{in} / \mu \mathrm{s})$ \\
\hline Separation & 0.76-mm (30-mil) cork material \\
\hline Contour & $533.4-\mathrm{mm}(21-\mathrm{in}$.$) radius$ \\
\hline \multicolumn{2}{|l|}{ Front Wedge } \\
\hline Length & $25.65 \mathrm{~mm}(1.01 \mathrm{in})$. \\
\hline Width & $25.4 \mathrm{~mm}(1.0 \mathrm{in})$. \\
\hline Height & 4.72-mm (0.186-in.) low point \\
\hline Incident angle & 9.0 degrees \\
\hline Roof angle & 4.66 degrees \\
\hline \multicolumn{2}{|l|}{ Back Wedge } \\
\hline Length & $27.84 \mathrm{~mm}$ (1.096 in.) \\
\hline Width & $25.4 \mathrm{~mm}(1.0 \mathrm{in})$. \\
\hline Height & 4.55-mm (0.179-in.) low point \\
\hline Incident angle & 13.707 degrees \\
\hline Roof angle & 4.66 degrees \\
\hline
\end{tabular}

The sound field simulation model was developed using the geometry of the specimen coupled with the as-built probe and wedge dimensions. The simulations were conducted with specimen assumptions of a homogeneous, isotropic material with a sound velocity of $5820 \mathrm{~m} / \mathrm{s}(0.2291 \mathrm{in} / \mu \mathrm{s})$, typical for longitudinal waves in wrought austenitic Alloy 600 materials. If the licensee were to make the mock-ups available for laboratory examination, the weld microstructure could potentially be analyzed to assess issues such as attenuation, scattering, and beam redirection. It should be noted that the assumption of a homogeneous, isotropic material means that the simulations and resultant probability of detection is greater than what would be expected in the actual weld material. Figure 2 shows the integral tandem probe mounted on the CAD specimen near the weld location in the circumferential scanning mode. 


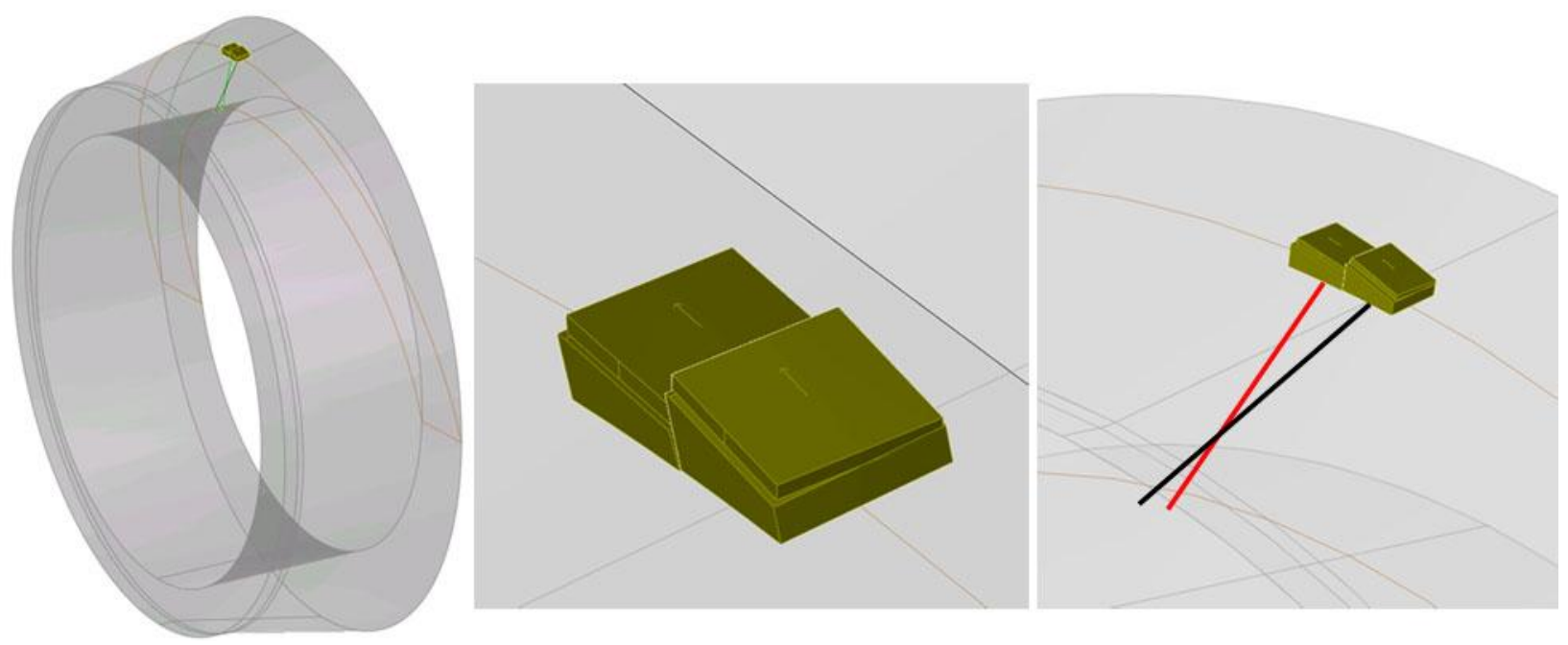

Figure 2. Tandem Probe Setup on DMW Specimen

Sound field simulations showing the acoustic beam density generated by the tandem probe are displayed in Figure 3. As depicted, simulated sound field energy increases from blue to red. The first image shows an unfiltered sound beam in the specimen; OD and ID surface locations are indicated. The middle image has a $-6 \mathrm{~dB}$ filter (50\% threshold) applied that highlights a $-6 \mathrm{~dB}$ focal zone. The image on the right of Figure 3 has the same $-6 \mathrm{~dB}$ filter applied without the full computational zone visible, emphasizing the insufficient extent of the $-6 \mathrm{~dB}$ focal zone (or highest intensity sound field) to reach the specimen ID surface region. The model indicates that this probe configuration is sensitive to longitudinal mode ultrasonic energy at a refracted angle of 30 degrees (not the licensee-designed 40 degrees), with the maximum value of sound field intensity located at $44 \mathrm{~mm}$ (1.73 in.) from the OD along the metal path. This result is based solely on probe specifications provided to PNNL by Sigma Transducers (probe manufacturer), and has not as yet been validated through empirical testing. The $-6 \mathrm{~dB}$ focal zone length along the metal path is $83 \mathrm{~mm}$ (3.27 in.) or only $56 \%$ of the entire through-wall metal path. The required metal path at 30 degrees to reach the ID is approximately $148 \mathrm{~mm}(5.83 \mathrm{in}$.).

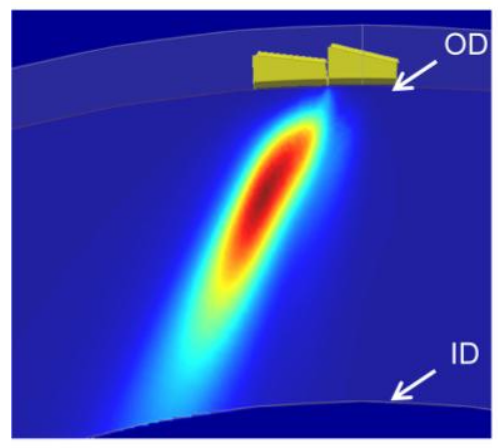

Sound beam

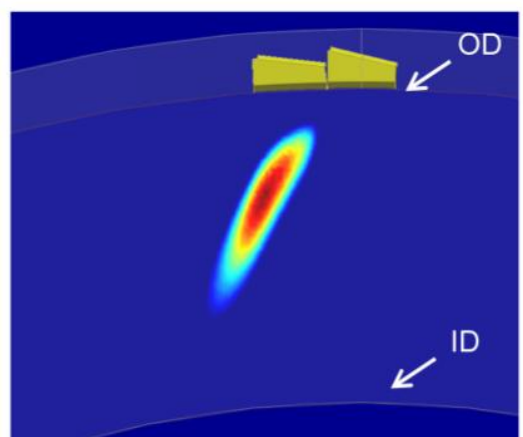

$6 \mathrm{~dB}$ focal zone

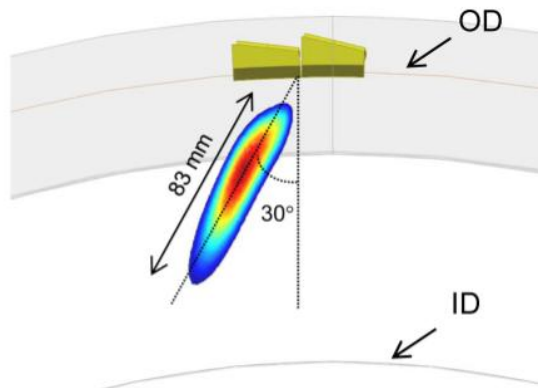

$6 \mathrm{~dB}$ focal zone

Figure 3. Sound Field Simulations and -6 dB Filter 
The simulated sound field was projected to the specimen ID, but was substantially diminished in strength $(-12 \mathrm{~dB}$ level). The image with an applied $-12 \mathrm{~dB}$ filter is shown in Figure 4 . A drop of $12 \mathrm{~dB}$ from the maximum sound intensity is a ratio of $4: 1$. Therefore, only about $25 \%$ of the maximum beam intensity is predicted at the ID surface; this is optimistic, given that a homogeneous, isotropic material was modeled versus the anisotropic nature of the weld microstructure. This reduction in signal level predicts a poor signal-to-noise level for detection of ID surface-connected flaws via a corner-trap response. The results suggest the tandem probe may potentially be suited for detection of specular or tip responses from flaws in the outer $60 \%$ of the material (which has only been modeled as simple isotropic media), but extremely limited for detection of ID-connected flaws in this specimen configuration.

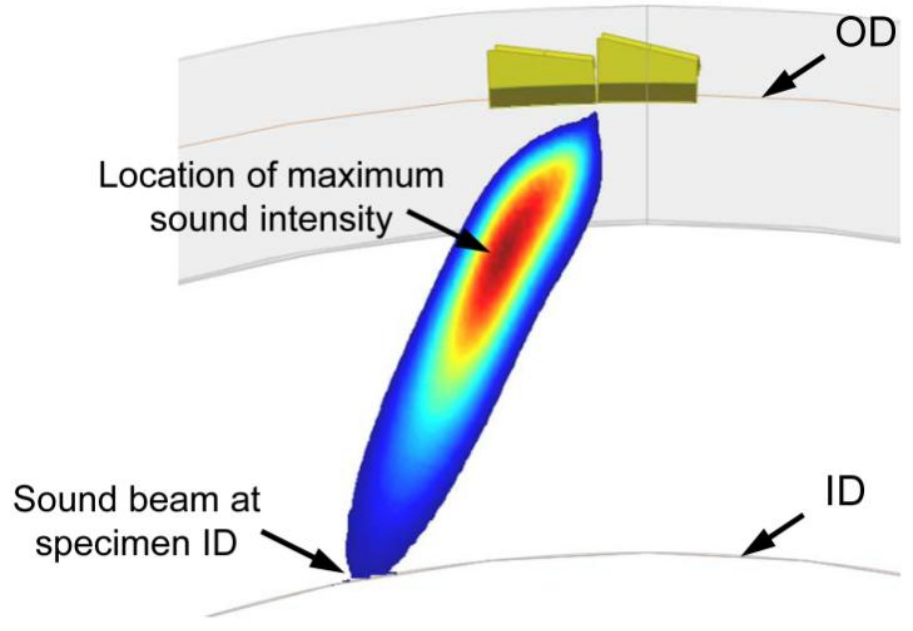

$12 \mathrm{~dB}$ focal zone

Figure 4. Simulated Sound Field at ID with a $-12 \mathrm{~dB}$ Filter

\subsection{Observations from North Anna Site Visit}

On May 2, 2012, two PNNL personnel accompanied a representative from the NRC's Office of Nuclear Regulatory Research on a site visit to the North Anna Power Station. Collectively, this team represents many years of ultrasonic testing experience in relation to complex weld materials and geometries. The purpose of the visit was to obtain first-hand information, using the licensee's tandem UT probes, cables, and ultrasonic instrument, on simulated flaws in the licensee's DMW mock-ups used to qualify the manual, non-encoded technique. This equipment included a GEIT USN-60, a portable, digitally controlled UT instrument typical of those employed by industry for manual examinations, and coaxial type cabling that was a standard $2 \mathrm{~m}(\sim 6 \mathrm{ft})$ in length. The probes are described in the previous section.

The licensee's mock-ups were fabricated by FlawTech, Inc. with implanted thermal fatigue cracks simulating PWSCC, as opposed to hot iso-statically pressed (HiP) notches, as is incorrectly stated in (TJ) IR-2009-358. Each mock-up represents an approximate 120-degree segment of DMW matching the configuration of the North Anna steam generator inlet pipe-to-nozzle weld, including the 11-degree OD 
taper on the safe end, DMW, and carbon steel nozzle. See Figure 5 showing a photograph of one of the North Anna mock-ups. Actual mock-up configurations, including implanted flaws sizes and locations, are provided in Attachment A [excerpted from (TJ) IR-2009-358].

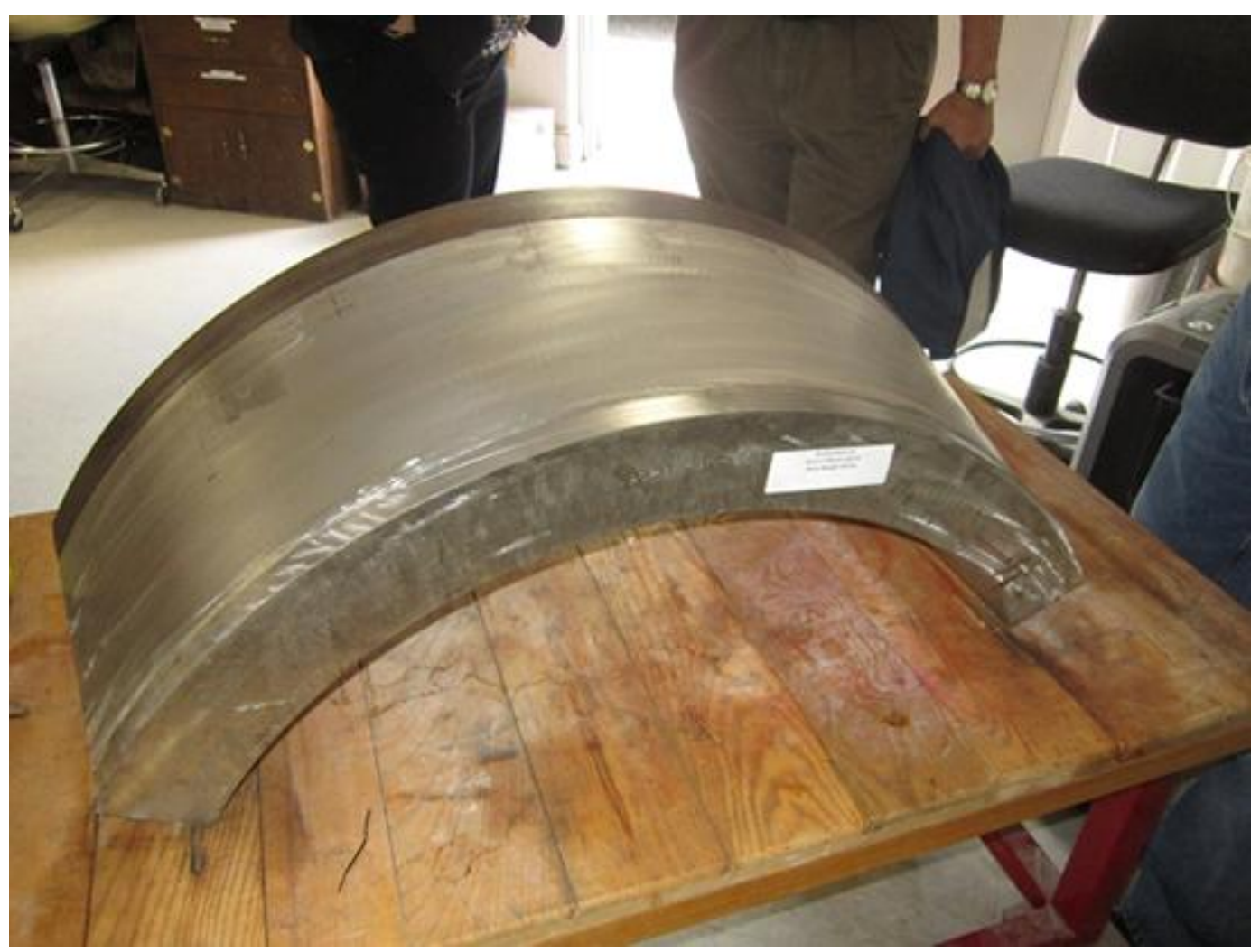

Figure 5. North Anna DMW Mock-up

\subsection{Mock-up DM-05}

This mock-up has one axial flaw that is reported to be approximately $32 \%$ in through-wall depth. The flaw was ultrasonically located with the "LR" probe at a marginal 2:1 signal-to-noise ratio (SNR). This flaw was also detected in the opposite scan direction with the "RR" probe, but with much less than 2:1 SNR. Several other mid-to-upper wall ultrasonic responses were observed along the weld length; these are potentially welding fabrication or, based on the location detected, implantation artifacts from circumferentially oriented flaws in the mock-up. The presence of these "spurious indications" in near vicinity to axial flaws is unusual for a demonstration mock-up. Plant-specific demonstration mock-ups should be used to train qualified examiners with respect to the special conditions that will be encountered in a particular examination. Normally, such mock-ups are fabricated such that flaws are discrete and highly detectable, so that examiners can be trained with respect to discriminating flaw responses from other reflections. The poor SNR and spurious indications made detection in the licensee's mock-ups significantly challenging, even when the locations of the targeted axial flaws are known. Figure 6 provides an example of the A-scan results showing typical mid-wall indications. 


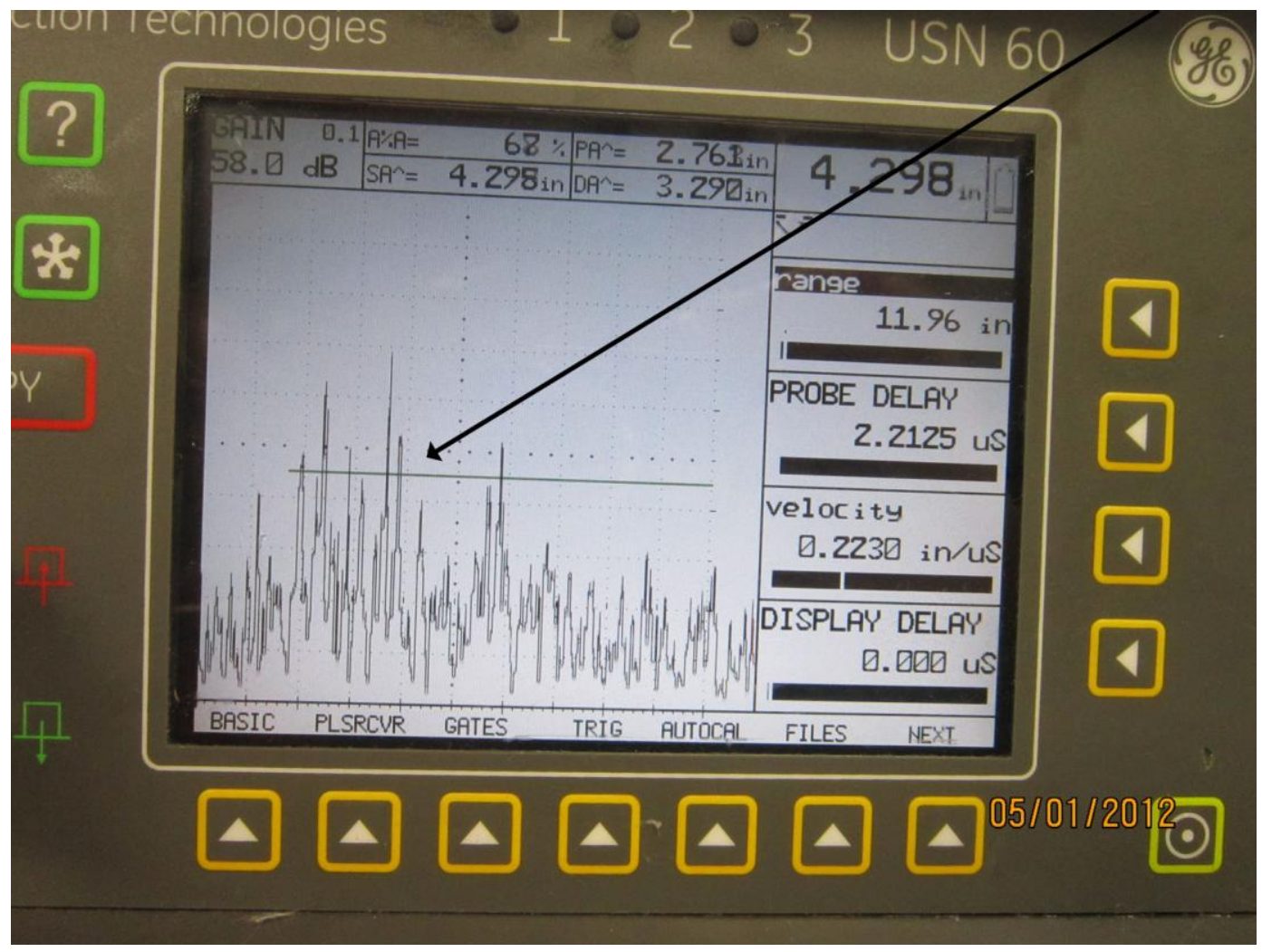

Figure 6. Mid-wall Fabrication Flaws or Implantation Artifacts Detected in North Anna Mock-ups (as indicated by arrow)

The end-of-block response from the mock-up, which represents a 100\% through-wall surface, was very easy to detect when scanning from the wrought safe end, but exhibited a significantly lower response when scanning through the weld material. In addition, the UT response from the end-of-block appeared to be slightly shifted out in time, indicating the weld microstructure may be re-directing the primary sound beam "upward" or at a higher inspection angle. There was a noticeable difference in sensitivity between the LR and RR tandem probes - this was on the order of 4 to $6 \mathrm{~dB}$ - and each set of probes exhibited a high-pitched "whine." This is unusual for an ultrasonic probe designed at this frequency when inductive tuning is not applied. As such, the cause for this whining noise is not understood.

\subsection{Mock-up DM-10}

Two axial flaws, reported as $17 \%$ and 51\% through-wall, respectively, were both detectable with the LR probe (less so with RR), and SNRs seemed similarly poor on this mock-up, when compared to the axial flaw on DM-05. Each pair of tandem probes required careful manipulation (slight skewing) for the SNR to reach near 2:1. Many larger responses (potentially fabrication flaws or implantation artifacts) were observed in DM-10 than in DM-05. However, like DM-05, these responses were also detected in the near vicinity of the axial flaw locations. The end-of-block response appeared somewhat higher in amplitude through the weld, which could indicate that the weld microstructure varies between DM-05 and DM-10. 
General observation - Given these mock-ups are claimed to be designed/fabricated to be consistent with ASME, Appendix VIII (ASME 2007), one would expect less inadvertent fabrication flaw, or implantation artifact, responses to be present. The UT responses from these artifacts, or weld fabrication flaws (this remains unclear), significantly impede detection and characterization of the axial flaws. Based on the site observations, there are too many transient indications detected on the North Anna mock-ups that interfere with targeted flaws for one to clearly assess the effectiveness of this non-encoded, manual system to detect the implanted cracks. Typical A-scan images for the flaws and other pertinent reflections on DM-05 and DM-10 are included as Attachment B.

\subsection{Assessment of EPRI Technical Justification}

A review was performed on several documents that are related to the inspection of the North Anna steam generator nozzle dissimilar metal weld configuration. The documents reviewed included Technical Justification for the Acceptance of Ultrasonic Examination Demonstration Results on North Anna Steam Generator Nozzle Dissimilar Metal Weld Configurations with PDI-UT-10, Rev. C (IR-2009-358) (EPRI 2009); Generic Procedure for the Ultrasonic Examination of Dissimilar Metal Welds, Rev. C (EPRI 2006); and Performance Demonstration Initiative (PDI) - Dissimilar Metal Weld Mock-Up Criteria Rev. A (EPRI 2004).

The PDI mock-ups were developed on the basis that certain weld geometries were plant-specific, and individual plants should be responsible for these types of mock-ups. As such, the DMW configurations that are represented in the blind test sets used at PDI to meet ASME Code, Appendix VIII, Supplement 10 requirements, are only those that are generic, or would typically be found in many plants. As a result, a guidance document was developed containing the criteria that site-specific mock-ups must meet. It is further stated in the abstract and introduction of (TJ) IR-2009-358 that site-specific mock-ups are used to optimize essential inspection variables and to demonstrate the effectiveness of the examination for the site-specific geometry. In the Abstract and Introduction Sections of the technical justification, essential variables that are allowed revision, or optimization, include:

- Alternative search unit angles

- Element size, focal depths, and contours of the search units

- Selection of compound angles to accommodate unique configurations (tapered inspection surfaces)

- Adjustment to scan patterns to compensate for limited access

- Other essential inspection variables as required.

As can be seen, this is a very broad statement that goes well beyond only "optimizing" essential inspection variables. In fact, this wording would appear to allow extension of, or deviation from, essential variables without the need to re-qualify a procedure, as is required by ASME Code, Section XI, Appendix VIII-3400. This approach undermines the intent of Appendix VIII to ensure that all inspections go through blind performance demonstrations to prove they are effective and robust. Furthermore, Appendix VIII, Supplement 10, Paragraph 4.0(d) requires that to qualify new essential variables, at least one personnel performance demonstration set is needed. Clearly, this requirement is not being met by what is allowed in (TJ) IR-2009-358, as applied at North Anna. Further, though Section 3 of (TJ) IR2009-358 assumes that the mock-up conditions are representative of actual in-service components, it is 
unclear whether the North Anna mock-ups adequately represent in-situ weld conditions, and the corresponding UT responses that would be expected for geometrical and metallurgical features in field welds. A review of the phased array UT data recently acquired on the North Anna DMWs could be compared to similar data on the licensee mock-ups to further assess this issue.

In Sections 4, 5, and 6 of (TJ) IR-2009-358, it is stated several times that changes in refracted angles were used to compensate for the North Anna 11-degree OD taper, but no modeling results or other calculations are included to support the position that impingement angles remain the same as those demonstrated during the original PDI qualification process. In addition, it would seem prudent to address the transducer aperture (overall size) at the frequency used so that one could confidently state that sufficient sound field energies would be present in the component to adequately insonify and detect flaws. This is a critical point and modeling results for the sound fields that were originally demonstrated along with those for the substituted transducers need to be presented in order to begin to build a case that ensures inspection performance has not been reduced or compromised. Yet, this basic acoustic information is not described in (TJ) IR-2009-358.

In Section 7 of (TJ) IR-2009-358, Table 7-1 and criteria paragraph 4.7.7, it is stated, "This mock-up was not commercially dedicated." The meaning of this statement is unclear. Further, under item 4.3 the document states, "An adequate number of flaws were strategically placed ---." However, at a minimum, the number of flaws should be representative of a single, full personnel performance demonstration set of flaws, according to Appendix VIII, Supplement 10, Paragraph 4.0(d). The mock-ups used by the licensee do not meet this criterion.

In the (TJ) IR-2009-358 (Section 8), it is stated, "For circumferential scans, the examinations can be performed from both nozzle and safe-end sides including the attachment weld area." When using conventional probes on DMWs having no, or minimal, OD taper, this is possible because the sound beam can be directed, or skewed, into the weld ID-area from the safe end and/or occasionally from the nozzle side. However, the tandem probe configuration at North Anna, which uses OD surface-conforming integral wedges to account for the diameter of the piping, may have effectively eliminated this option because of the lateral skew designed into the integral wedges to account for the 11-degree OD taper. In theory, this re-direction of the sound beam, via wedge roof angles, is necessary to produce a sound field at the correct orientation (relative to the axial direction of the pipe) at the ID surface in this narrow weld region. Therefore, the only transducer placement area for which the sound would be skewed properly is directly over the weld OD surface, and an attempt to use this tandem configuration from either the safe end or nozzle side would not re-direct the sound beam into the correct weld area to detect PWSCC, if it occurs.

With respect to the number of relevant axial flaws in the mock-ups for conducting the non-blind demonstration, (TJ) IR-2009-358 states that two of the three axial flaws that exist in the North Anna mock-ups are "out of range" as specified in PDI Dissimilar Metal Weld Mockup Criteria, Rev. A and are for "information only." This implies that only one axial mock-up flaw could be used to assess inspection technique validity, since two of the three axial flaws are essentially "out-of-compliance" with the mockup criteria; this could significantly impact the rigor of the demonstration for axial flaw detection.

In Section 9 of (TJ) IR-2009-358, it is stated under the headings of Ultrasonic Hardware, Cabling and Transducers, that "No previous transducer and ultrasonic equipment combinations exist." However, it is assumed that some combination of these items had been demonstrated at PDI for initially meeting 
Supplement 10, and equipment substitution would be used for situations such as North Anna to compensate for the 11-degree taper configuration. The statement in (TJ) IR-2009-358 is not understood and needs further explanation.

Section 11 of (TJ) IR-2009-358 states that, "the taper is the only geometric challenge for the [North Anna] examination that is offset by an adjustment of the examination angles and ultrasonic transducer manufacturing parameters." If this is the only challenge for this site-specific examination, it is unclear why previously qualified transducers (through blind testing) could not simply be modified to account for the taper, rather than using probes that had never been qualified through blind performance demonstration. Finally, it is stated that "The parameters for the design and fabrication of these sitespecific mock-ups are consistent with ASME Appendix VIII requirements." This statement is incorrect, in that the North Anna mock-ups (as a set) do not actually conform to the requirements listed in ASME Code, Appendix VIII, Supplement 10. For instance, there are only 8 flaws in the North Anna set as compared to the minimum 10 flaws required by Supplement 10. In another example, Supplement 10, Paragraph 2.1(b) states "Specimens shall have sufficient volume to minimize spurious indications that may interfere with the interpretation process." As noted in the previous section of this report describing observations made during the North Anna site visit, mid-wall UT responses, potentially from welding fabrication or circumferential flaw implantation, interfere with detection of the axial flaws. Also, Section 11 of (TJ) IR-2009-358 reports that all implanted flaws were successfully detected with a 2:1 SNR or better during the on-site open demonstration. The 2:1 SNR value is highly questionable, based on examinations conducted by PNNL and NRC staff on the actual North Anna mock-ups, probes, and inspection system.

The ASME has developed new Code Case N-780 entitled, "Alternative Requirements for Upgrade, Substitution, or Reconfiguration of Examination Equipment When Using Appendix VIII Qualified Ultrasonic Examination Systems." This Code Case provides an alternative to current ASME Code rules to address the upgrade, substitution, or reconfiguration of essential ultrasonic system components. While this Code Case was developed subsequent to (TJ) IR-2009-358 and thus was not available to address the issue of substituting new transducers to accommodate the taper on the North Anna DMW configuration, it is interesting to note that EPRI has taken the position that if one uses the Code Case, a blind demonstration test must be passed. This position seems to be in opposition to that stated in (TJ) IR-2009358 , where an open demonstration process is used.

Nevertheless, new Code Case N-780 provides certain guidance for what is needed to make a case for equipment substitution. It is suggested that industry and the NRC work together to create a process that is acceptable to both for use of this Code Case. Additionally, ASME Appendix VIII, Supplement 5 provides excellent guidance on the requirements that site-specific nozzle-to-vessel weld mock-ups and procedures need to meet in order to show that essential inspection variables are within the bounds of the previously qualified demonstrations. This would appear to be a good starting model for site-specific Supplement 10 requirements and getting these placed into ASME Code would be an important step in reviewing and improving them for wider use. 


\subsection{Conclusions}

The failure of the licensee's UT technique to detect multiple, deep through-wall cracks on the subject DMW erodes confidence in nondestructive examination techniques that are being applied for site-specific PWSCC inspections, and further, casts doubt on certain protocols being used under the auspices of PDI for qualification of procedures, personnel, and equipment.

Ultrasonic modeling of specific probe parameters for the manual examinations employed on the subject DMW configuration at North Anna indicates that insufficient acoustic energy would be available near the inner surface of the weld to assure detection of ID surface-connected axially oriented flaws. These results further suggest inadequate performance for manual, real-time examinations to properly discriminate and characterize surface-connected flaws from other welding or metallurgical features in the inner one-third of the weld volume on these DMWs. This finding is corroborated by site observations that show low SNR for the targeted mock-up flaws in the presence of spurious indications that interfere with detection and classification of simulated ID-connected cracks.

The technical justification lists the probe's angle as being 40 degrees as impinged on the ID surface. Modeling shows that the effective angle for the subject probe configuration is, in actuality, approximately 30 degrees. The apparent discrepancy places the licensee's use of this probe out of compliance with their own procedure and (TJ) IR-2009-358. It should be noted that this angle discrepancy is based solely on modeling, given the probe parameters provided by the manufacturer, as no empirical tests have been performed to validate these results. Based on site observations of all UT responses in the North Anna mock-ups, one would not expect the applied manual, non-encoded technique to consistently detect axial flaws (with low numbers of false calls) without examiners having prior knowledge of where these flaws are located. Thus, if the mock-ups, tandem probes, and scanning techniques used at North Anna were subjected to blind performance demonstrations using realistic implanted flaws, the procedure would, in our estimation, have significantly poor qualification pass rates.

As noted in Section 4.0, site observations revealed too many transient indications in the North Anna mock-ups that interfere with targeted flaws for one to clearly assess the effectiveness of this non-encoded, manual system to detect cracks. In addition, site observations of the UT responses for the simulated flaws implanted in the mock-ups and other fabrication features raised questions with respect to whether the mock-ups represent typical metallurgical and other fabrication features of DMWs in-situ. In order to sufficiently judge the adequacy of protocols being used under the auspices of PDI for qualification of procedures, personnel, and equipment, it would be necessary to acquire comparable data on both the field welds and mock-ups.

The technical justification developed to extend PDI qualifications to North Anna DMWs has been found inadequate to make a reasonable case for using the manual, non-encoded procedure that was employed. The primary issue associated with (TJ) IR-2009-358 is one of allowing essential variables to be changed without providing sufficient technical bases for these changes. For instance, a physics-based technical assessment, either through calculations or modeling, has not been included to support the manual tandem probe design. The condition of the mock-ups, as fabricated, and the "open" nature of the site qualifications, raise further concerns relative to the validity of (TJ) IR-2009-358 to justify changes in demonstrated variables (essential or non-essential) necessary to accommodate the 11-degree taper on the subject DMW configuration at North Anna. Therefore, the effectiveness of these changes is questionable. 
Considering these issues, it has been determined that the site-specific approach implemented at North Anna does not meet the intent or stated requirements of Appendix VIII.

ASME Appendix VIII is a framework that has been developed to support procedure, personnel, and equipment (UT system) qualifications through rigorous and statistically based testing protocols. Technical justifications such as (TJ) IR-2009-358, as written, enable licensees to implement changes to any essential variable in a qualified procedure simply by stating that this change is necessary for implementation at their site. This approach enables licensees to bypass Appendix VIII requirements and, therefore, potentially erode the expected performance of qualified UT systems. Code Case N-780 provides a much more robust methodology for implementing such changes in essential variables.

Finally, there appears to be an inconsistency with respect to the application of robust, blind demonstration approaches versus less rigorous, open qualifications. This issue has been highlighted as a result of the North Anna incident, where the licensee requested that EPRI review (TJ) IR-2009-358 to reassess the current validity of the information provided within this document. With respect to the open demonstration process, EPRI has determined the stated position (of using an open demonstration process) in (TJ) IR-2009-358 to continue to be acceptable, which is inconsistent with their approach to the use of Code Case N-780, where EPRI requires that a blind demonstration test be passed. This inconsistency needs to be further discussed and a path forward defined in order to develop guidance for application during either type of performance demonstration.

\subsection{References}

ASME. 2007. "Section XI, Rules for Inservice Inspection of Nuclear Power Plant Components;

Appendix VIII, Performance Demonstration Requirements for Ultrasonic Examination Systems." In 2007 ASME Boiler and Pressure Vessel Code - An International Code. American Society of Mechanical Engineers, New York.

EPRI. 2004. Performance Demonstration Initiative (PDI) - Dissimilar Metal Weld Mock-Up Criteria $R E V$ A. Electric Power Research Institute, Palo Alto, California.

EPRI. 2006. Generic Procedure for the Ultrasonic Examination of Dissimilar Metal Welds. PDI UT10, Revision C, Electric Power Research Institute, Palo Alto, California.

EPRI. 2009. Technical Justification for the Acceptance of Ultrasonic Examination Demonstration Results on North Anna Steam Generator Nozzle Dissimilar Metal Weld Configurations with PDI-UT-10, Rev. C. IR-2009-358, Electric Power Research Institute, Palo Alto, California. 


\section{Appendix A}

\section{Description of North Anna Mock-ups}





\section{Appendix A}

\section{Description of North Anna Mock-ups}

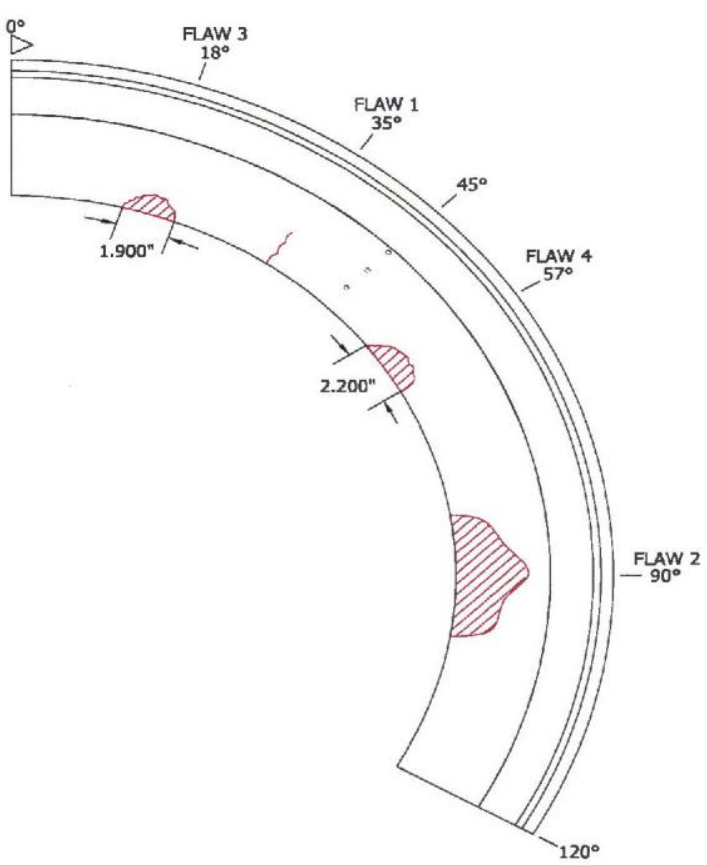

Figure A.1. North Anna NPS Steam Generator Nozzle Mock-up PQ-31-DM-05

Table A.1. Flaw Information for PQ-31-DM-05

\begin{tabular}{|c|c|c|c|c|c|c|c|c|c|c|c|}
\hline \multirow{3}{*}{$\begin{array}{c}\text { Flaw } \\
\text { No. }\end{array}$} & \multicolumn{5}{|c|}{ Flaw } & \multicolumn{3}{|c|}{ End Ref. to } & \multicolumn{2}{|c|}{ Location } & \multirow{3}{*}{$\begin{array}{l}\text { OD to ID } \\
\text { Thickness } \\
\text { (T) }\end{array}$} \\
\hline & \multirow[b]{2}{*}{ Type } & \multirow[b]{2}{*}{ Orient. } & \multirow[b]{2}{*}{ Length } & \multicolumn{2}{|c|}{ Depth } & \multirow{2}{*}{$\begin{array}{c}\text { Flaw } \\
\text { CL }\end{array}$} & \multirow{2}{*}{$\begin{array}{c}\text { Flaw } \\
\text { Tip }\end{array}$} & \multirow{2}{*}{$\begin{array}{l}\text { Flaw } \\
\text { Base }\end{array}$} & \multirow[b]{2}{*}{ Circ. } & \multirow[b]{2}{*}{ Deg. } & \\
\hline & & & & Height & $\%$ of $\mathrm{T}$ & & & & & & \\
\hline 1 & Crack & Axial & $1.200 "$ & $1.600 "$ & $32.5 \%$ & $2.637 ”$ & N/A & N/A & $11.475^{\prime}$ & $35^{\circ}$ & $4.920 "$ \\
\hline 2 & Crack & Circ & $5.010 "$ & $2.441 "$ & $49.6 \%$ & N/A & $2.547 ”$ & $2.417 ”$ & $29.508 "$ & $90^{\circ}$ & 4.920” \\
\hline 3 & Crack & Circ & $1.900 "$ & $0.818^{\prime \prime}$ & $15 \%$ & N/A & $2.486 "$ & $2.411 ”$ & $6.588^{\prime \prime}$ & $18^{\circ}$ & 5.444” \\
\hline 4 & Crack & Circ & $2.200 "$ & $0.934 "$ & $17 \%$ & N/A & 2.513” & $2.485 "$ & $20.862 "$ & $57^{\circ}$ & 5.443” \\
\hline
\end{tabular}




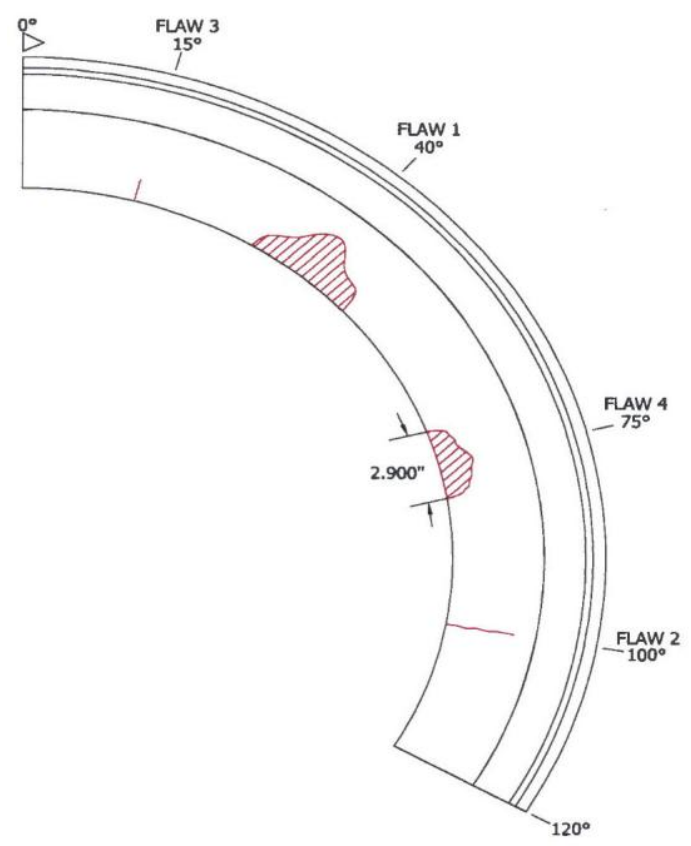

Figure A.2. North Anna NPS Steam Generator Nozzle Mock-up PQ-31-DM-10

Table A.2. Flaw Information for PQ-31-DM-10

\begin{tabular}{|c|c|c|c|c|c|c|c|c|c|c|c|}
\hline \multirow{3}{*}{$\begin{array}{c}\text { Flaw } \\
\text { No. }\end{array}$} & \multicolumn{5}{|c|}{ Flaw } & \multicolumn{3}{|c|}{ End Ref. to } & \multicolumn{2}{|c|}{ Location } & \multirow{3}{*}{$\begin{array}{l}\text { OD to ID } \\
\text { Thickness } \\
\quad(\mathrm{T})\end{array}$} \\
\hline & \multirow[b]{2}{*}{ Type } & \multirow[b]{2}{*}{ Orient. } & \multirow[b]{2}{*}{ Length } & \multicolumn{2}{|c|}{ Depth } & \multirow{2}{*}{$\begin{array}{c}\text { Flaw } \\
\text { CL }\end{array}$} & \multirow{2}{*}{$\begin{array}{c}\text { Flaw } \\
\text { Tip }\end{array}$} & \multirow{2}{*}{$\begin{array}{l}\text { Flaw } \\
\text { Base }\end{array}$} & \multirow[b]{2}{*}{ Circ. } & \multirow[b]{2}{*}{ Deg. } & \\
\hline & & & & Height & $\%$ of $\mathrm{T}$ & & & & & & \\
\hline 1 & Crack & Circ & $4.251^{\prime \prime}$ & $2.085^{\prime \prime}$ & $42 \%$ & N/A & $2.752 ”$ & $2.447^{\prime \prime}$ & $14.399 "$ & $40^{\circ}$ & $4.920 "$ \\
\hline 2 & Crack & Axial & $1.377^{\prime}$ & $2.485 "$ & $51 \%$ & 2.797" & N/A & N/A & $35.848^{\prime \prime}$ & $100^{\circ}$ & 4.920” \\
\hline 3 & Crack & Axial & $1.001 "$ & $0.941 "$ & $17 \%$ & $2.810^{\prime \prime}$ & N/A & N/A & 5.490" & $15^{\circ}$ & $5.490 "$ \\
\hline 4 & Crack & Circ & $2.900 "$ & $1.262 "$ & $23 \%$ & N/A & $2.630 "$ & $2.634 "$ & $27.450 "$ & $75^{\circ}$ & $5.455^{\prime \prime}$ \\
\hline
\end{tabular}




\section{Appendix B}

\section{A-scans on North Anna Mock-ups}



DRAFT

Appendix B

\section{A-scans on North Anna Mock-ups}

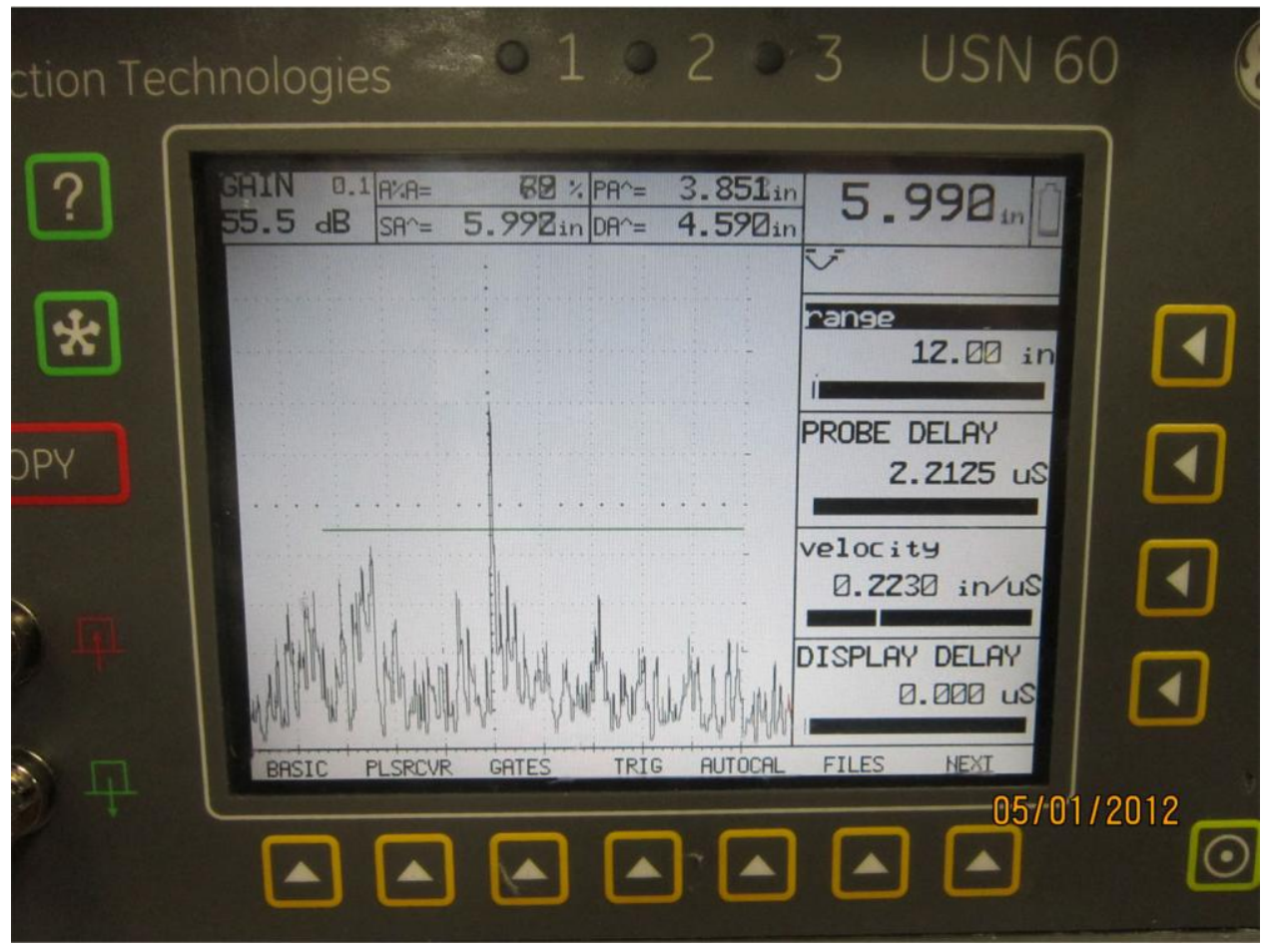

Figure B.1. DM-05 32\% Through-Wall Axial Flaw with LR Probe 


\section{DRAFT}

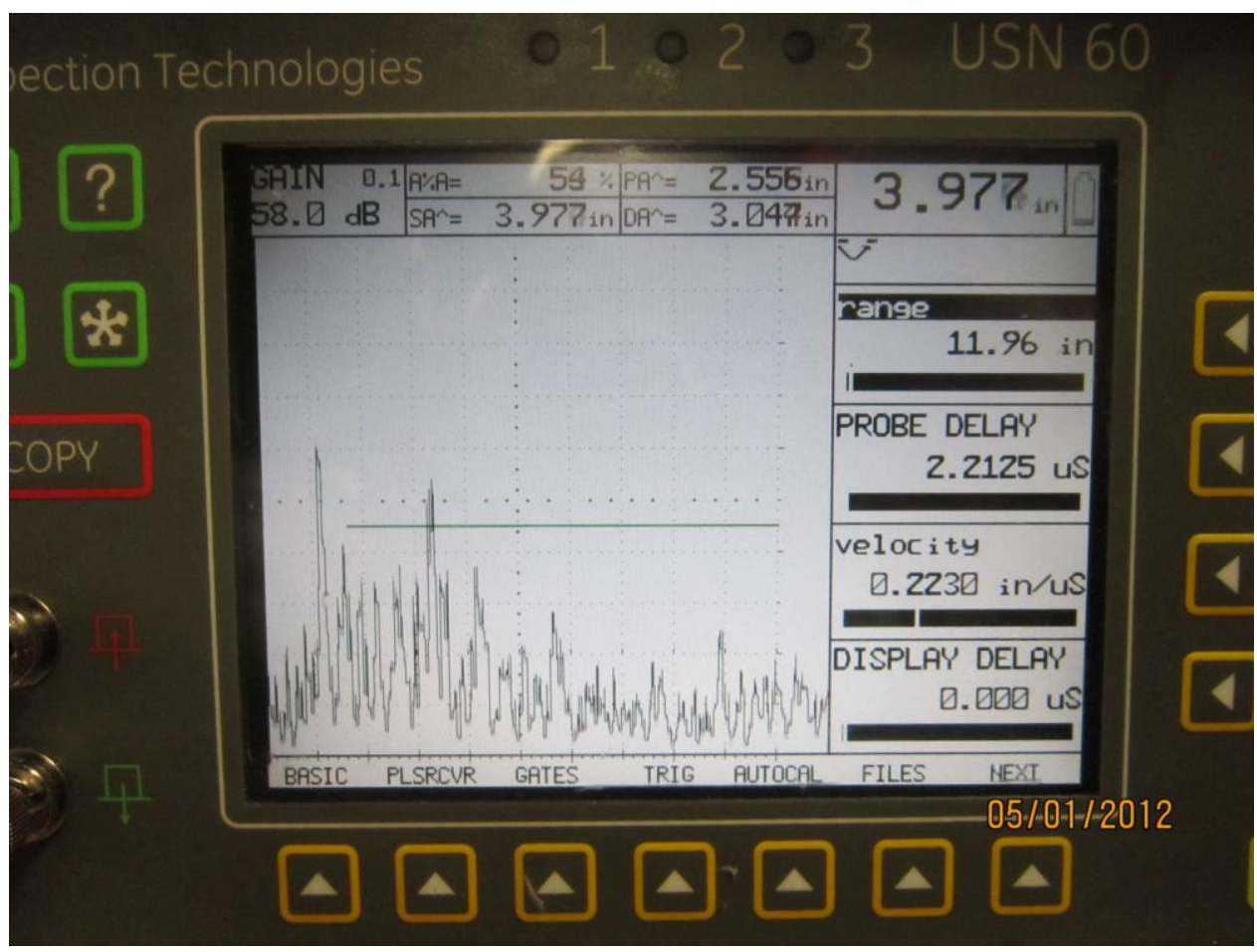

Figure B.2. DM-05 Fabrication/Implantation Flaws

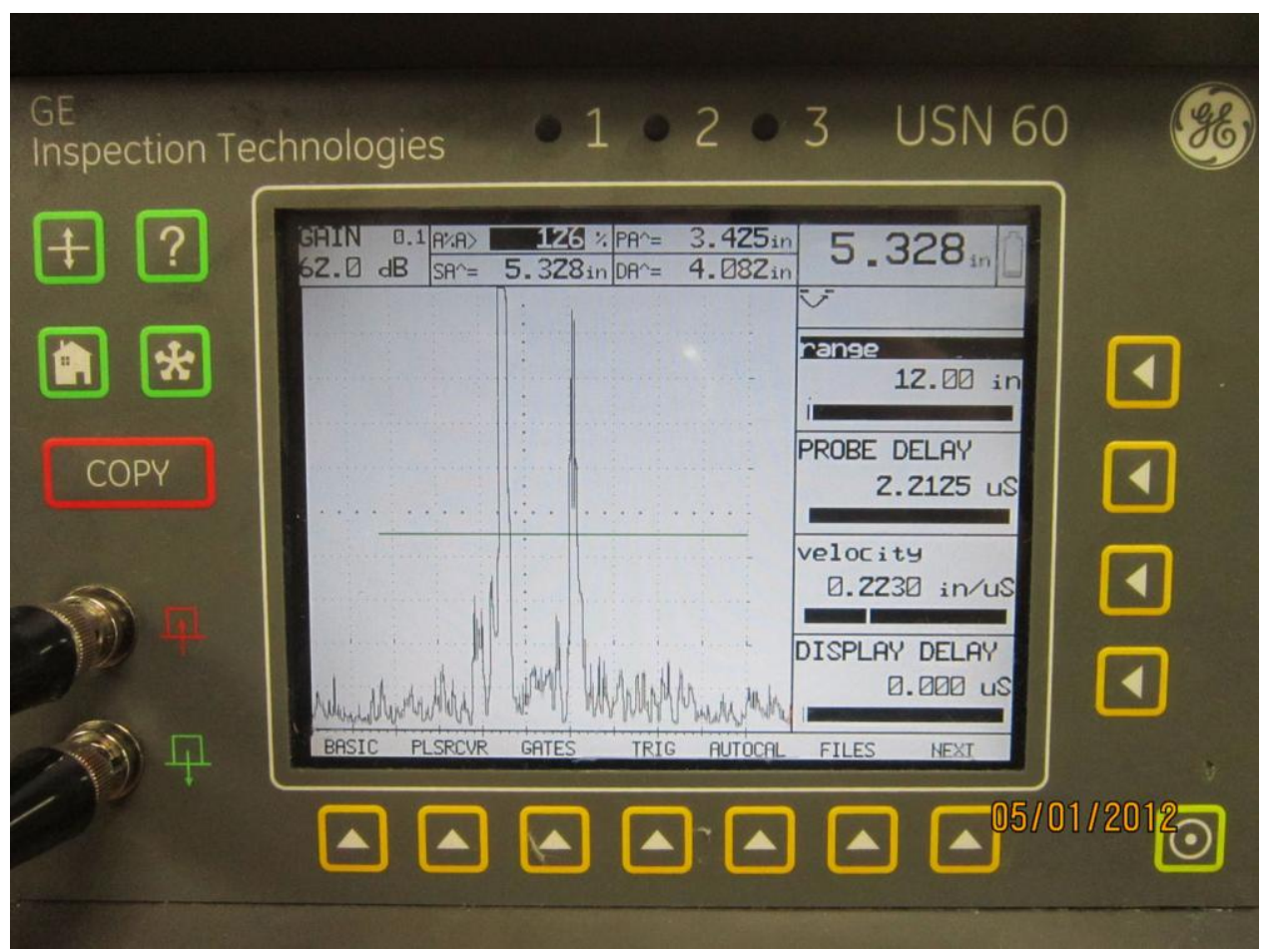

Figure B.3. DM-05 End-of-Block Through Safe End 


\section{DRAFT}

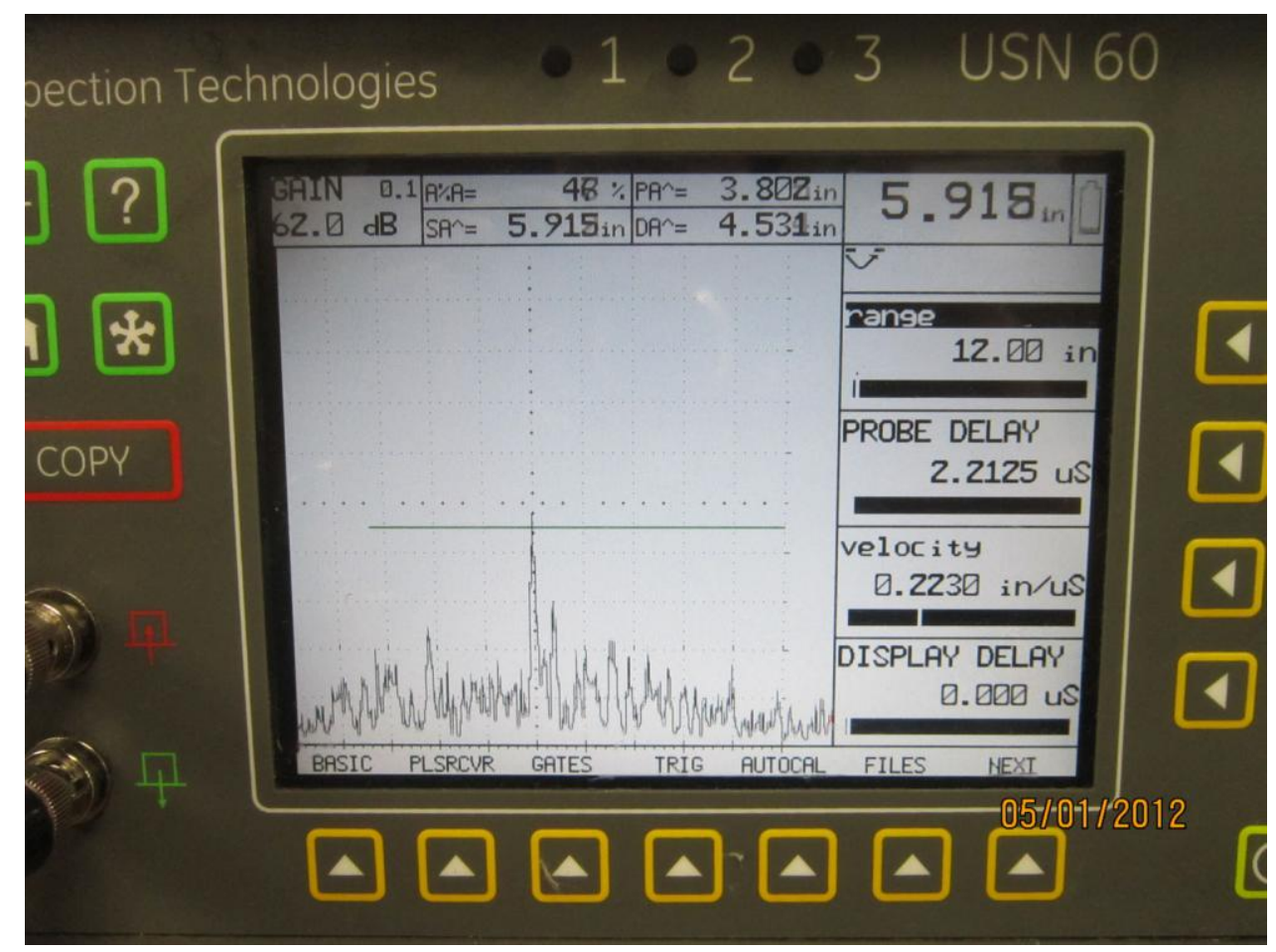

Figure B.4. DM-05 End-of-Block Through Weld

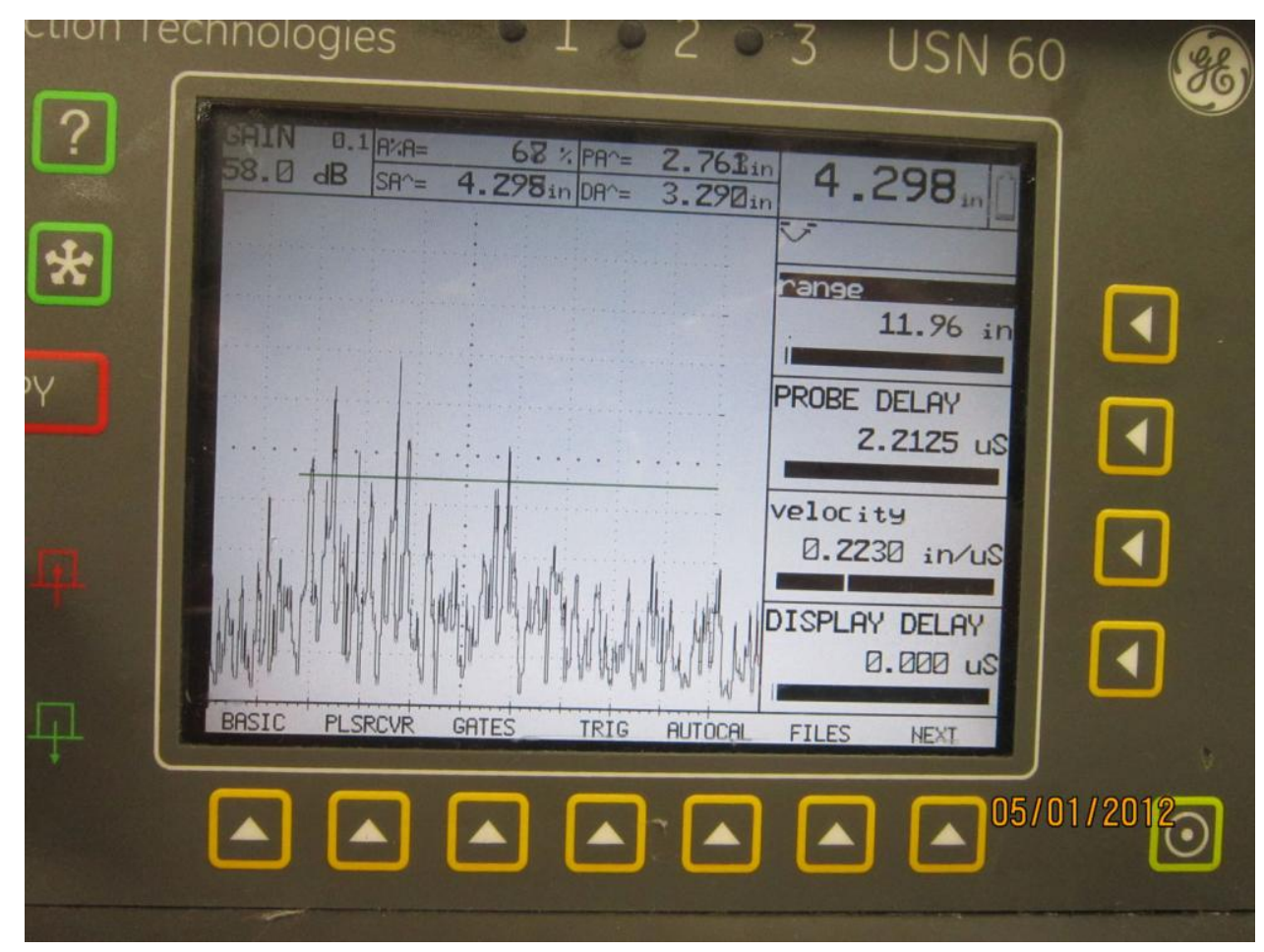

Figure B.5. DM-10 Fabrication/Implantation Flaws 


\section{DRAFT}

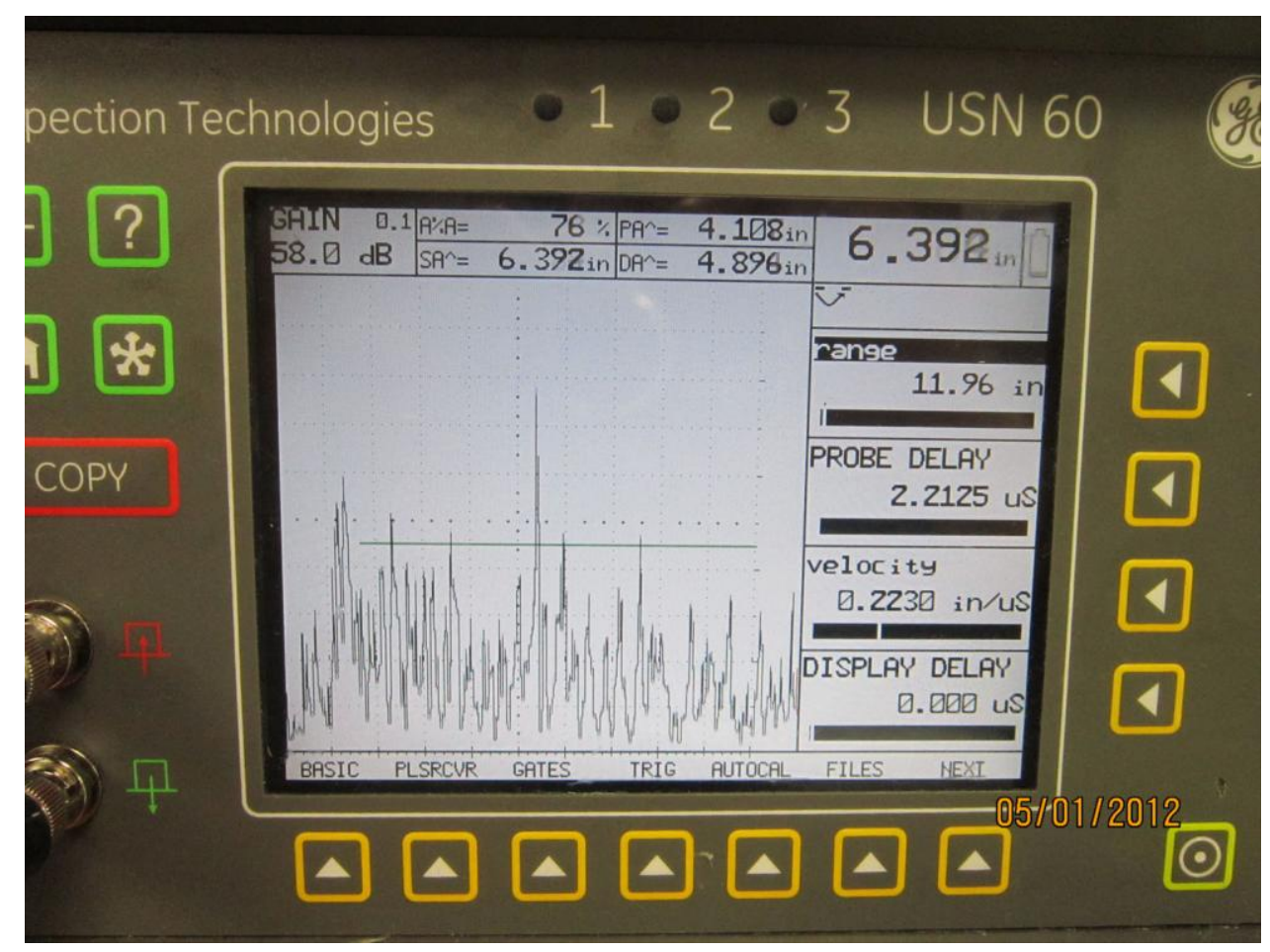

Figure B.6. DM-10 17\% Through-Wall Axial Flaw with LR Probe

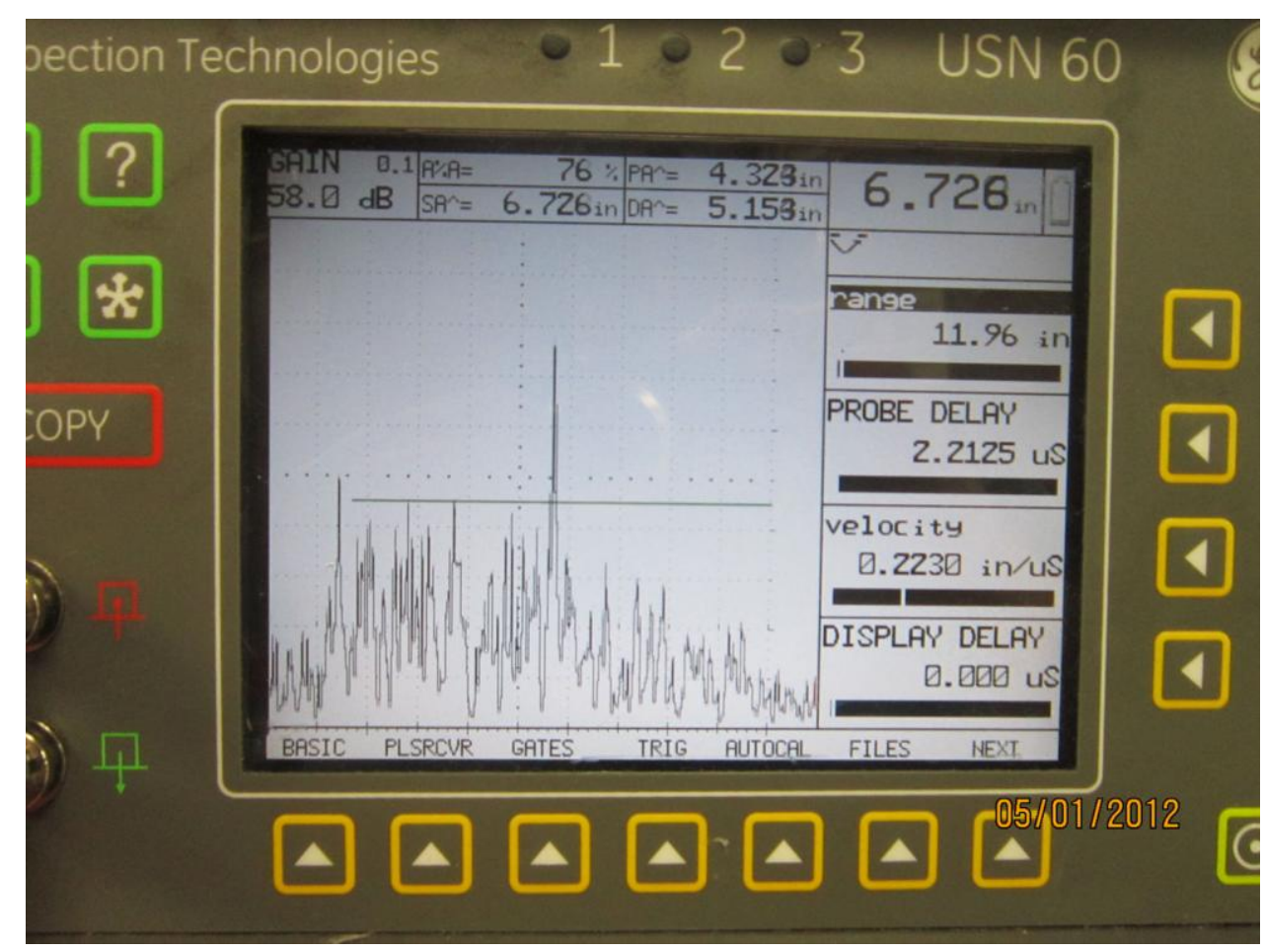

Figure B.7. DM-10 51\% Through-Wall Axial Flaw with LR Probe 



\section{DRAFT}

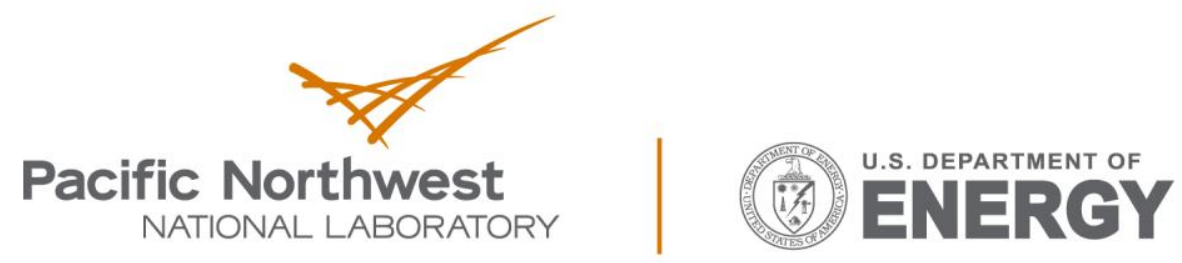

Proudly Operated by Battelle Since 1965

902 Battelle Boulevard

P.O. Box 999

Richland, WA 99352

1-888-375-PNNL (7665)

www.pnnl.gov 